\title{
Self-management of Function in Older Adults: The Contribution of Physical Therapy
}

\author{
Julie Richardson • Vanina Dal Bello-Haas • \\ Adalberto Loyola-Sanchez • Joy MacDermid • \\ Susanne Sinclair
}

Published online: 10 August 2013

(C) Springer Science+Business Media New York 2013

\begin{abstract}
The increase in chronic disease and associated musculoskeletal impairment experienced by a rising number of older persons will contribute to a surge in the prevalence of disability globally. The prevention of functional decline and the challenge of maintaining optimal functioning is complex and understudied. This review explores how physical therapy principles are applied within self-management (SM) programs for older adults with chronic illnesses. A search was conducted for papers that evaluated a chronic disease SM intervention involving a physical therapist (PT) delivered to older adults. In the papers reviewed, physical activity was the predominant focus of the SM interventions. Nine studies measured mobility and five studies reported positive functional outcomes. When mapped to the ICF classification of functioning, there were more positive findings at the level of body functions and structure in the arthritis studies compared to the COPD studies, where there were more positive findings at the level of participation. Future research and development needs to focus on integrating theoretical frameworks and rehabilitation-derived SM into PT practice.
\end{abstract}

Keywords Self-management $\cdot$ Chronic disease $\cdot$ Physical therapy $\cdot$ Older adults $\cdot$ Rehabilitation

\author{
J. Richardson $(\varangle) \cdot$ V. D. Bello-Haas $\cdot$ A. Loyola-Sanchez $\cdot$ \\ J. MacDermid $\cdot$ S. Sinclair \\ School of Rehabilitation Science, Faculty of Health Sciences, \\ McMaster University, 1400 Main Street West, Hamilton, \\ ON L8S 1C7, Canada \\ e-mail: jrichard@mcmaster.ca \\ V. D. Bello-Haas \\ e-mail: vdalbel@mcmaster.ca \\ A. Loyola-Sanchez \\ e-mail: loyolaa@mcmaster.ca \\ J. MacDermid \\ e-mail: macderj@mcmaster.ca \\ S. Sinclair \\ e-mail: ssincla@mcmaster.ca
}

\section{Introduction}

It is projected that a worldwide increase in the number of older adults combined with the global rise in chronic diseases will contribute to an unprecedented surge in the prevalence of disability [1]. The majority of older persons experience multiple comorbid diseases and [2] chronic musculoskeletal diseases are ranked as the second most prevalent cause of disability worldwide [1]. The interaction between the effects of aging and the physical changes associated with these chronic health problems result in barriers to maintaining optimal function as a component of health outcomes. The prevention of functional decline is complex and insufficiently studied. A recent systematic review attempted to determine the effectiveness of interventions that could mitigate functional decline. This review concluded that it was not currently possible to determine the overall benefit of the interventions from the studies because of the methodological heterogeneity; there was too much diversity in the sample selection with respect to risk for functional decline, the spectrum of outcomes measured was too broad and the outcome measures employed were suboptimal and inconsistently used [3•]. The purpose of this review is to provide an overview of the studies that have examined self-management (SM) interventions involving physical therapy which targeted functional outcomes for older adults with chronic illnesses.

\section{Self-Management and Older Adults}

For the purpose of this review, we used the definition of selfmanagement (SM) that we have used in a previous review [4]. Briefly, SM is when a person with a chronic disease engages in activities to protect his/her health, monitors and manages the symptoms of illness and manages the impact of illness on functioning along with emotions and interpersonal relationships [5]. A SM program is a multi-component strategy that 
aims to promote and support adequate SM for persons with chronic diseases by supporting each of these dimensions [6]. There is a generic set of skills that participants of chronic disease SM programs (CDSMPs) acquire, including problem solving, decision making, action planning, overcoming barriers and setbacks, accessing resources, managing and developing relationships with their healthcare providers, and tailoring health care and community interventions $[7,8 \bullet]$.

Loss of self-management abilities has been associated with loss in different functioning domains, including physical functioning. Changes in physical functioning are a better predictor of loss of self-management skills than chronological age. Selfmanagement skills associated with function are needed by persons with chronic disease to prevent and manage functional decline [9]. Older adults are less likely than younger adults to participate in programs involving health promotion. Older persons who do participate are more likely to be more highly educated [10,11], female [11, 12], younger [13, 14], have a higher socioeconomic status $[10,15,16]$ and are more interested in adopting positive health behaviours [10, 16, 17]. A recent study that examined predictors associated with attendance at a 6-week CDSMP found that persons who had higher function were twice as likely to attend compared to those with lower function, while frequency of exercise and Patient Activation Measure scores (a measure of self-management) were not associated with attendance [18]. Overall, evidence suggests that there is a subset of persons in need of SM who are difficult to engage in the process.

\section{Physical Function as a Primary Health Outcome}

Increasing evidence suggests that function should be considered as a sixth vital sign and should be assessed as a primary health outcome [19-21]. Functional status as an outcome of care is a major concern for persons with chronic illness, regardless of age, who are trying to self-manage their condition. Thus, increasing awareness about the relationship between physical function and the patient's overall health status will not only assist physicians and other members of the health care team to build their capacity in assessing functional status but will likely improve the care for persons with chronic illness. Physical function and mobility issues in the context of an individual's overall health status will supersede impairment issues because the former are predictive of independence and autonomy for the older person. An initial step in making assessments in primary care more salient to appropriate health outcomes in the elderly would be to implement tests of function [21]. Min and Shekelle (2012) have recently called for a globally accepted measure of functional decline, as the lack of a universal model to categorize older persons into functional subgroups acts as a barrier to empirically driven decisionmaking about prognosis and treatment interventions [22•].
They have proposed a model called FRAME (Functional Reserve Assessment Map for Elders) that would provide a framework for clinically meaningful assessment of physical function.

Mobility disability Mobility, the ability to move independently within one's environment, is essential to maintaining independence in personal and instrumental activities of daily living (ADLs) [23]. Changes in mobility are frequently the first indication of functional decline [24]. Mobility disability, a highly dynamic process, is often indicative of health status [25]. Mobility disability is characterized by frequent transitions between states of mobility independence and mobility limitation (disability) [26]. These cumulative transitions of a person's life-long mobility form a mobility trajectory. Mänty (2007) hypothesized that major mobility disability develops through stages of preclinical mobility limitation and more minor mobility limitation [27]. Preclinical mobility limitation is a stage in the natural history of functional change when there is the opportunity for primary prevention interventions. Preclinical mobility difficulties can be reliably identified when adults modify the frequency, method, and time taken to complete walking tasks $[28,29]$. The prevalence of preclinical limitations with mobility tasks in community dwelling samples has been reported as ranging from $20-40 \%$ [30], and from $31-55 \%$ in adults over 75 years [27]. Persons in the preclinical mobility limitation stage are at increased risk for the onset of disability and for the early onset of disease [28, 29]. Persistent deterioration in mobility is a predictor of mortality and has been reported in the absence of changes in activities of daily living over a two year period [31].

There are identified thresholds of muscle strength that are required to perform ADLs $[32,33]$ and walking and mobility [34-37]. Normative data for community dwelling older adults for self-selected walking speed has been established as an average of $1.34 \mathrm{~m} / \mathrm{s}$ for men and $1.24 \mathrm{~m} / \mathrm{s}$ for women 60 69 years [38•]. Handgrip strength as a measure of overall strength has been used to identify thresholds for walking or climbing stairs with cut off points for the likelihood of mobility limitations for men being $37 \mathrm{~kg}$ (sensitivity $62 \%$; specificity, $76 \%$ ) and $21 \mathrm{~kg}$ for women (sensitivity $67 \%$; specificity $73 \%$ ). Decrements in muscle strength result in impaired mobility and the development of functional limitations, frailty, and disability $[39,40]$. There are well established assessments of lower extremity function [41] and lower extremity muscle strength with age and sex based norms that can guide a targeted intervention and advice for the older person. Changes in gait or walking speed are predictive of the onset of further disability and dependency [25, 42], and as a result, gait speed is often used as an indicator of health status.

Educating the older person about changes that are occurring in their function and mobility in the context of selfmanagement is a potentially effective way for the physical 
therapist to give them insight into their own functional status and engage them in discussions regarding a targeted and tailored action plan which may involve linking with evidence-based community resources [43].

\section{Frameworks to Address the Contribution of Self-management to Maximizing or Optimizing Function}

There are three frameworks that can be used to inform work in SM:

1. Service delivery frameworks. The Chronic Care Model (CCM) http://www.improvingchroniccare.org and the Expanded Chronic Care Model (ECCM) [44•] are approaches to planned, proactive, population-based, evidenced based and patient-centered care to manage chronic illness. [45-47]. The six dimensions of the CCM are (1) organization of health care (health and design systems), (2) selfmanagement support, (3) decision support, (4) clinical information systems such as the electronic medical record through which patients' functioning can be monitored or self-management supported, (5) delivery system support, and (6) community resources. Productive interactions between providers and patients to support self-management within organizations need to be enhanced [47].

2. Functioning frameworks. The two major frameworks around functioning are: (1) the International Classification of Functioning, Disability and Health (ICF) and (2) the Disability framework, which has four stages (active pathology, impairment, functional limitation, and disability) $[48,49]$. A third conceptual schema was proposed by Glass (1998) and distinguishes between the capacity to function in the abstract, which is typically self-report and performance (hypothetical tense and experimental), and actual performance in daily life (enacted tense) [50].

A fourth conceptual explanation which informs functioning is the reserve capacity theory, which has two components: (1) functional performance threshold expressed as a certain level of strength, endurance and flexibility, required for the patient to complete their ADLs, and (2) functional capacity expressed as the ability to make physiological adaptations to respond to demanding activities above this basic level. The difference between the functional capacity and the functional performance threshold is called the functional reserve. The ability to respond to challenging tasks decreases with age and chronic illness(es). When it drops below the functional performance threshold, the patient will no longer be able to do basic tasks independently and will have to depend on others for help [51].
3. Behavioral frameworks. Two behaviourally focused models on which the principles of SM are focused include goal setting, barrier identification, problem solving, goal modification, peer support, action planning and selfregulation as components. Self-regulation can be defined as an iterative, guided, goal-directed process that requires an individual to be self-reflective while engaging in a change process aimed at task- and time-specific outcomes and requires motivational and self-regulatory skills [52-54]. SCT defines concepts to explain adherence behavior $[55,56]$. Self-efficacy and outcome expectations for positive behavior change are important mediators to these theories. Both of these can be used to understand, implement and utilize the self-management process.

The current role of the PT profession within the conceptualization of SM is not clear. The objective of this review is to explore how physical therapy principles are applied within SM interventions for older adults with chronic illnesses and how they impact on the outcomes of interest. A secondary objective is to identify the theoretical framework cited and how it was used to develop or implement the intervention.

\section{Search Strategy and Methodology}

We searched MEDLINE (1946 to February 2013), Embase (1988 to February 2013), AMED (Allied and Complementary Medicine from 1985 to February 2013), PsycINFO (1987 to February 2013), CINAHL and SportDiscus for English language papers using a combination of the following search terms: physiotherapy or physical therapy, self-care or selfmanagement and physical function or functional decline. A manual search of the reference lists of relevant papers was also conducted to identify any studies missed using this search strategy. Papers were included if: (1) they described a chronic disease self-management intervention involving a physiotherapist; (2) the mean age of the study population was $\geq 65$ years; (3) changes in physical functioning or functional decline were measured; and (4) the design was a randomized controlled trial (RCT). The titles and abstracts of all identified papers were screened and papers that met the inclusion criteria were identified (see Fig. 1). Two authors (JR, SS) extracted the data using a data extraction form. Once papers were systematically identified and included, then they were classified by disease. Following this we extracted information about: (a) theories or theoretical concepts used by the authors of each paper; (b) the components of the SM interventions focusing on the PT contribution; and (c) the outcomes utilized by the authors of each paper.

We also mapped the theories or theoretical concepts reported in the papers to one or more of our three main theoretical 
Fig. 1 Search strategy. $A M E D$ Allied and Complimentary Medicine; CINAHL Cumulative Index to Nursing and Allied Health Literature; SM Selfmanagement; PT Physical therapist

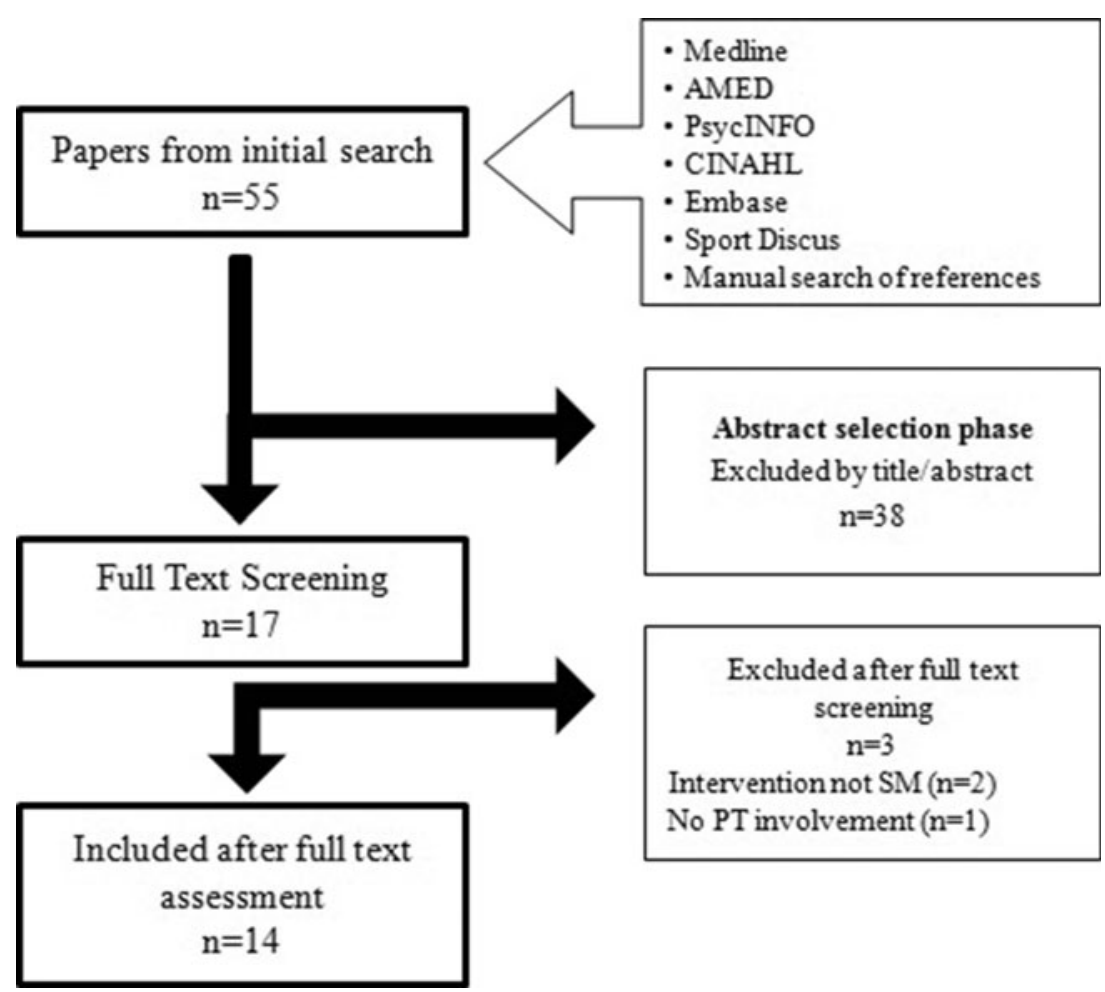

frameworks (service delivery, functioning and behavioral) and described the SM intervention and outcome measures of each paper in the terms of the three main theoretical constructs considered in this review. In our review related to Functional Capacity Theory, we assumed that all PT-led SM interventions were directed to increase the "functional reserve" of participants. Therefore, two authors (SS, AL) reviewed the characteristics of the PT-led SM interventions provided in the selected papers and determined how the "functional reserve" was addressed. The reviews were conducted separately and then disagreements were solved through dialogue and consensus.

\section{Results}

The search yielded 55 papers; of those, the majority were excluded by screening the title and abstract $(n=41)$. The 14 remaining papers underwent full text analysis. There were three condition/disease specific areas (arthritis, osteoporosis and osteopenia, chronic obstructive respiratory disease) and several studies of generic chronic conditions where physiotherapy principles in the SM context were explored. The findings will be described under these headings (See Table 1).

\section{Arthritis}

The Osteoarthritis of the Knee Self-Management Program (OAK) is a disease-specific self-management program offered within a primary care setting that was evaluated using an RCT. Participants engaged in a 6-week program (2.5 hours per week), with assessments at baseline, 8 weeks and 6 months [57••].The SM program was delivered by health care professionals and was based on SCT with the goal of enhancing selfefficacy and promoting sustained behavior change. Physiotherapists delivered the program using a facilitators' manual which covered the following topics: medications/ analgesia (interactions, side effects, doses and polypharmacy), pain management strategies (cognitive and pharmacologic) fitness and exercise (strength, flexibility, aerobic and balance) joint protection, nutrition and weight control, fall prevention (balance and proprioception), environmental risk, coping with negative emotions, SM skills and the team approach to health care $[57,58 \bullet \bullet, 59 \bullet \bullet$. The target group size was twelve participants. Detailed information about exercise was offered by the therapist at every session, including instruction and demonstration. A comprehensive home exercise program was encouraged and incorporated the components noted above [58••]. The authors distinguished between the OAK and the disease specific Arthritis Self-Management Program (ASMP). Mobility was assessed using the Timed Up and Go (TUG) [60]. There were significant differences in favor of the OAK group at 8 weeks and 6 months on the main outcomes of physical function (WOMAC and SF36- Role Physical) and total WOMAC scores between baseline and 6 months. Pain scores were comparable between the groups. There was a difference on the TUG but it was not clinically significant. The authors emphasize the importance of having health 


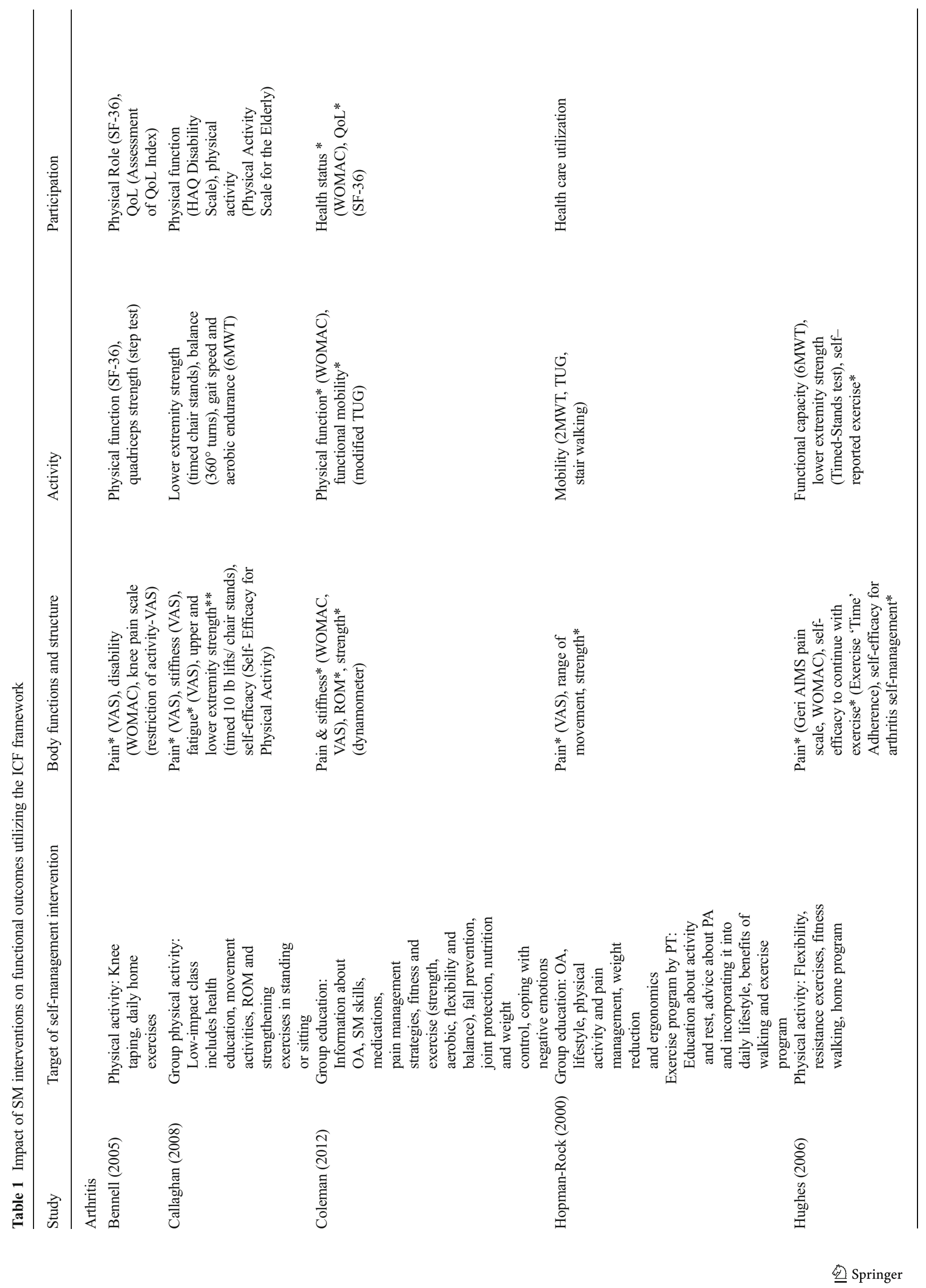




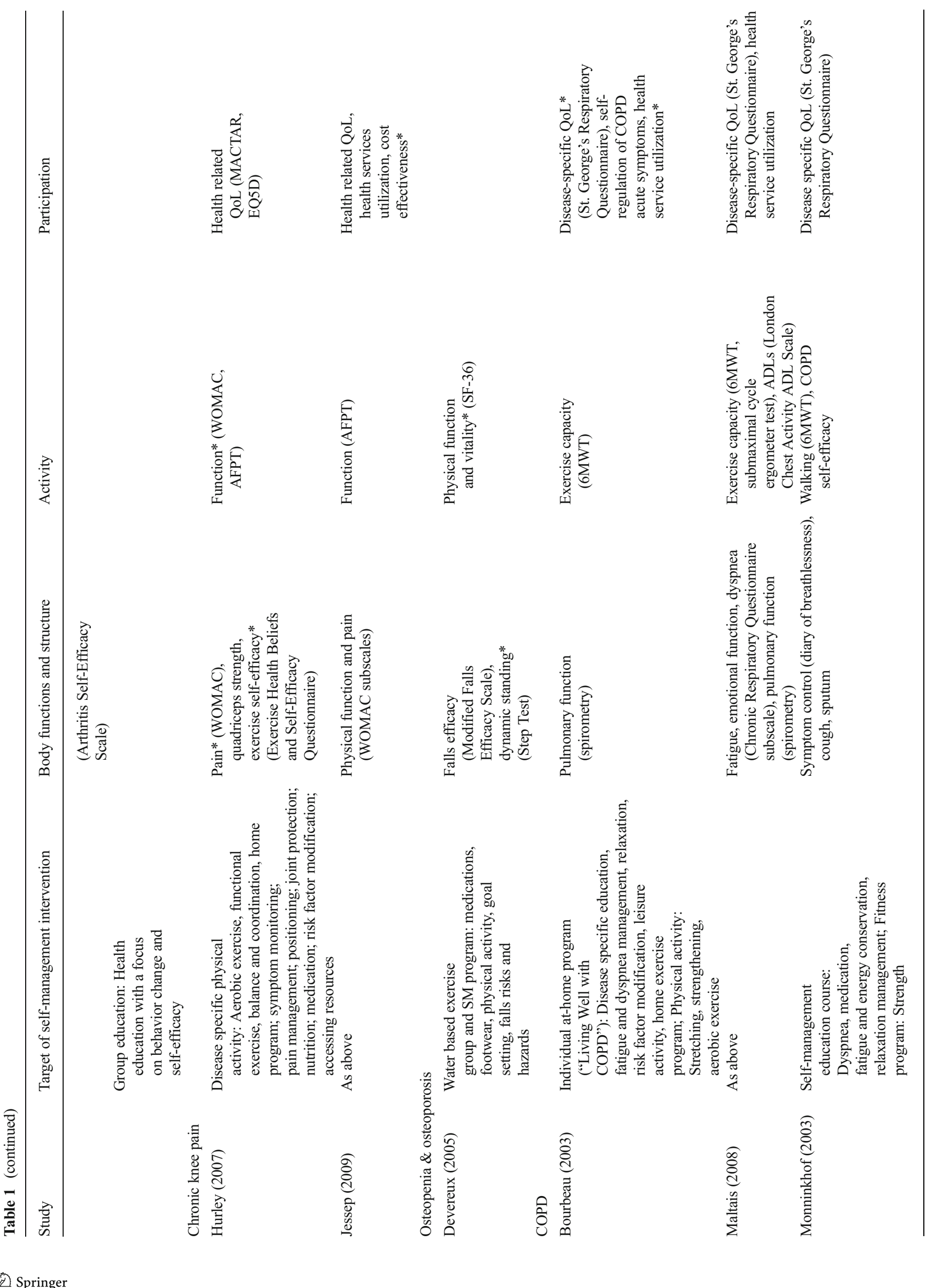




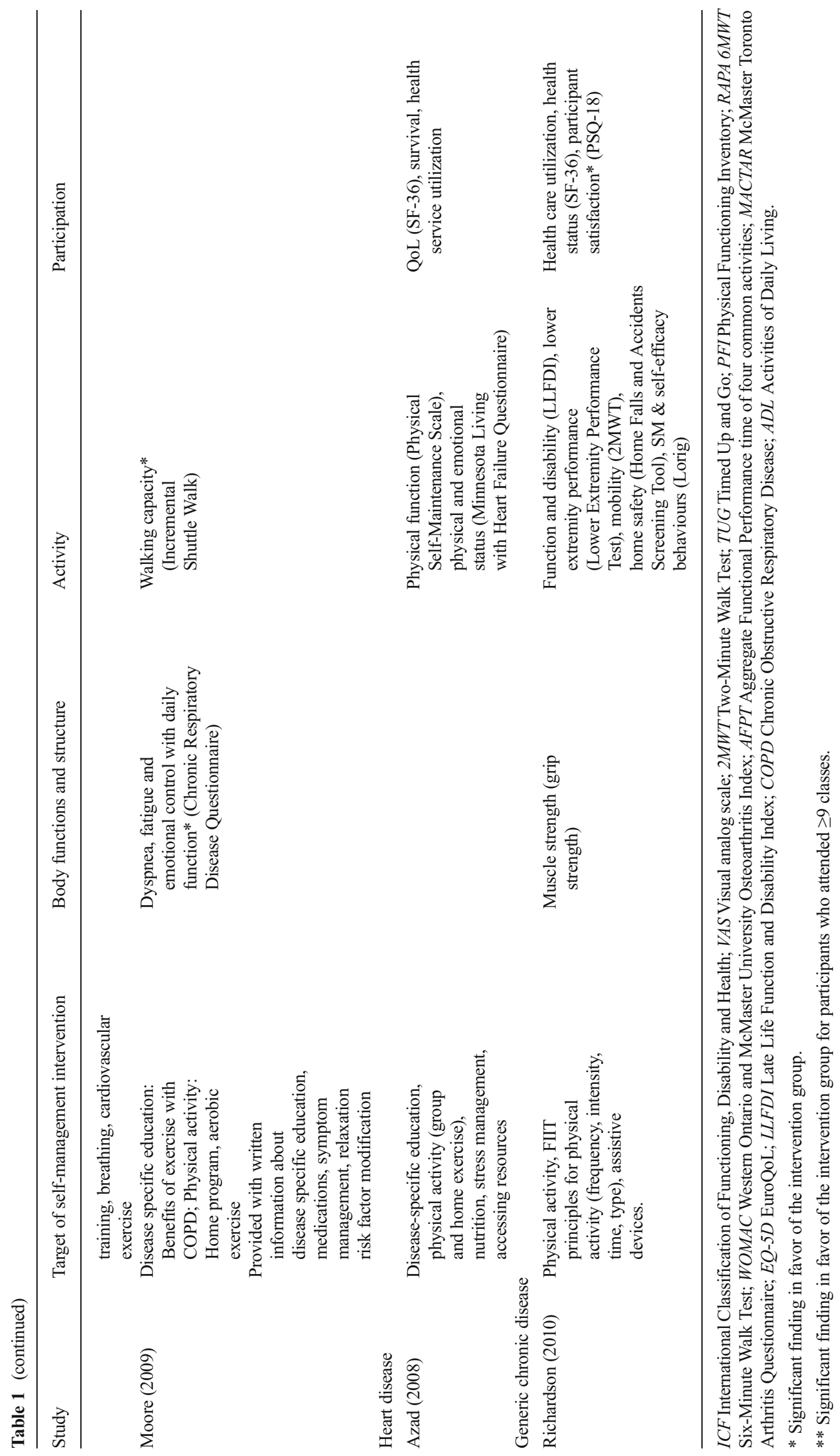


professionals with expertise in musculoskeletal function lead the program, since they have the knowledge and skill to convey information about the disease and its management that lay-leaders are lacking [59••].

Two further studies evaluated the effectiveness of SM programs in people with OA where a PT was involved in the design and delivery of the interventions. One RCT, $(n=105$, mean age $=65$ years $)$ focused on mainly women $(83 \%)$ with hip and knee OA and involved group exercise, a home exercise program, pain management, nutrition and disease-specific education. They used strategies such as goal setting, problem solving, planning and self- regulation to deliver the intervention in two parts. First, a peer educator discussed weight and pain management, physical activity and ergonomic aspects of activity. In the second hour, a PT taught an exercise program incorporating education about the balance between rest and activity, preferred types of exercise and integrating them into daily activities and the benefits of walking. Mobility was measured using the subscale of the International Rheumatology General Health and Lifestyle (IRGL) [61]. The intervention was delivered in weekly 2-hour sessions for 6 weeks and participants were assessed at 6 weeks and 6 months followup. There were significant effects for pain, quality of life, quadriceps strength, knowledge, self-efficacy, BMI, increased physical activity and decreased visits to a PT. There were no effects for range of motion, mobility or functional tasks [62].

The People with Arthritis Can Exercise Program (PACE) was evaluated in another study for persons with self-reported arthritis $(n=321$, mean age $=70$ years, $80 \%$ female $)$ at 8 weeks, and follow-up about physical activity levels at 3 and 6 months. The program targeted the SM of arthritis through exercise and cited no theoretical framework. There were two measures of mobility, gait speed and the 6-Minute Walk Test (6MWT). There was an improvement in pain, fatigue and self-efficacy outcomes but there was no significant difference in function or mobility. The classes were offered for one hour, $1 \mathrm{x}$ weekly for 8 weeks, and persons who attended $\geq 9$ sessions showed a significant improvement in upper and lower extremity strength as measured by chair stands [63].

In summary, all three studies demonstrated improvements

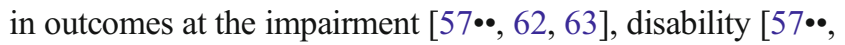
62] and participation level (i.e., healthcare utilization) [57••, 62]. There was some improvement in performance/objective tests for mobility $[57 \bullet \bullet, 63]$, however specific mobility benefits were not demonstrated in assessments where the PT evaluated mobility [62]. The follow-up period was generally short (6 months) and inconsistent across outcomes [63] and the effect sizes were small to moderate post-intervention and sustained but reduced at follow-up.

Several RCTs have examined the efficacy of SM programs to manage osteoarthritis (OA) of the knee specifically. A 12week program of SM was used to deliver a multimodal PT program including taping, mobilization, exercises and massage in private practices to participants $(n=140$, mean age $=68$ years). Knee taping, home exercise and log book documentation were continued for a further 12 weeks post intervention and were considered part of the SM, versus a control who received sham ultrasound. There was no theoretical framework described to develop the intervention. Physical function was assessed using the WOMAC and SF-36 physical function, quadriceps strength and a step test but there was no performance test of mobility. There was no difference between the groups in pain (VAS), health status, quadriceps strength or balance [64]. The authors concluded that the intervention which included a SM component was not more effective than regular visits to a physical therapist.

The ESCAPE-knee pain program is a rehabilitation program involving exercise, SM and active coping strategies. It included disease specific education, physical activity, aerobic exercise, functional exercise, balance and coordination, symptom monitoring, pain management, joint positioning, nutrition, medication risk factor modification and accessing resources. The impact of the intervention on functioning in persons with chronic knee pain was compared with usual primary care (whatever the primary care physician considered appropriate). Participants ( $n=418$, mean age $=67$ years $)$ received the intervention in 30-minute sessions, $2 \times$ weekly for 6 weeks. To ensure consistency in content and delivery, the same physiotherapist tailored and progressed all exercise programs. There was no performance measure of function or mobility. The improvement on the function, pain and total scores for the WOMAC functional performance, time and exercise health beliefs, anxiety and depression and QoL were greater for the intervention group [65].

The ESCAPE-knee pain program was later compared to outpatient physiotherapy by Jessep (2009). A PT led a themebased discussion at the beginning of each session followed by a progressive exercise session to improve strength, balance, co-ordination and function. Participants $(n=64$, mean age $=67$ years) received the 1 hour intervention $2 \mathrm{x}$ weekly for 5 weeks and received a tailored home exercise program and information about community resources. They were also offered a one hour review session after 4 months. There was no theoretical framework cited to support the intervention and no performance based assessment of mobility or function. The intervention group showed greater improvement in exerciserelated beliefs and self-efficacy and cost effectiveness but no difference in the reported physical function or pain subscales of the WOMAC, ADLs, anxiety and depression, healthrelated quality of life or health services utilization [66].

In a study by Hughes (2006), an iterative problem solving approach to SM was designed to enhance arthritis self-efficacy for both exercise, exercise adherence, pain management and other arthritis related symptoms. It was used as part of a multicomponent exercise intervention for adults $(n=215$, mean age $=$ 73.3 years) with mild to moderate hip/knee OA and was led by a 
PT. Participants were asked to sign individualized postintervention exercise contracts and complete daily exercise logs, and were encouraged to maintain home-based physical activity programs. The intervention was based on SCT with self-efficacy being an important mediator to sustained behavior change [67]. The authors also followed a Negotiated Adherence Model [68] and the process model for patient-practitioner collaboration [69]. Participants received 90 minute sessions $3 \mathrm{x}$ weekly for 8 weeks. Mobility was assessed using the 6MWT [70] and lower extremity performance using chair stands [71]. There were positive outcomes in favour of the intervention group for arthritis self-efficacy, exercise adherence and self-efficacy, adherence to the program, maintenance of physical activity and the pain and stiffness subscales of the WOMAC. There were no between group differences on the performance measures (the 6 MWT or the sit-to-stand test) $[72,73]$.

In summary, the evidence to date for SM interventions to manage knee OA in older persons, two of which described theoretical frameworks for their interventions, showed an increase in self-efficacy for exercise and exercise adherence and improvement in self-reported pain and function [65, 72, 73] Neither of these studies included an objective measurement of mobility. The remaining three studies had no theoretical underpinnings to support the interventions [64-66] ; two of these studies showed no significant difference between the groups on any outcomes $[64,66]$ while one study did show a significant change in self-reported functional outcomes [65]. It is surprising that only one study included an observed test of mobility $[72,73]$.

\section{Osteopenia and Osteoporosis}

A self-management program was combined with a 10 -week water-based exercise program targeting balance, fear of falling and quality of life for community-dwelling older women $(n=50$, mean age $=73.3$ years $)$ with a diagnosis of osteopenia or osteoporosis. The program was conducted by a PT and was offered in 1-hour sessions 2x weekly [74]. The control group received no intervention and was not encouraged to change their physical activity. Topics covered in the 10-minute education SM component prior to the water-based intervention related to osteoporosis, medications, footwear, physical activity, goal setting, home exercise programs and falls risks and hazards, all of which were reinforced while exercising. These sessions used self-assessment questionnaires to identify risks and weekly goal setting and diary review to address modifiable risks, checklists, group brainstorming and exercise diaries. The intervention group showed improved outcomes compared to the control on the Step Test as a test of dynamic standing balance, and four of the eight domains on the SF-36 including the physical function, vitality, social function and mental health. There were no between group differences on the fear of falling measure (Modified Falls Efficacy Scale). There was no measure of mobility and no specific outcome measure used to assess the effect of the SM component of this intervention which makes it difficult to assess its specific contribution to the overall effects. The actual time spent on SM was minimal compared to the water-based intervention and there was no SM framework or theory from which the intervention was developed. Both groups achieved the maximum score on the fear of falling measure at baseline so it is difficult to estimate whether there was a change in selfefficacy as a result of the intervention. The use of SM with this population offered in conjunction with a water-based intervention to improve balance and manage fear of falling needs further development and examination [74].

\section{Chronic Obstructive Pulmonary Disease (COPD)}

Three studies have evaluated self-management interventions for older persons with COPD using randomized designs. An early Canadian study ( $n=191$, mean age $=70$ years) used education, problem solving, self-regulation and individual coaching to deliver an 8-week program entitled Living Well with COPD. Participants were followed by telephone for one year to examine the effect of the program on use of hospital services and health status. The participants received an individually based program. It had no theoretical framework and included disease-specific education, fatigue management, relaxation and dyspnea management, symptom monitoring and a home exercise program compared to a usual care group [75]. Assessments were completed at 4 and 12 months. There was reduced utilization of health services, improved QoL and greater regulation of COPD symptoms but no improvement in exercise capacity or pulmonary function measures for the participants who received the intervention [75]. There was no selfreported or performance measure of physical functioning.

A similar SM program in the Netherlands posited SelfEfficacy Theory as the underlying framework and included dyspnea management, medication, relaxation, physical therapy, leisure activity, a home exercise program, ergonomics and nutrition as part of the SM intervention and compared it to usual care [76]. Education, goal setting, self-regulation, coaching and peer support were strategies used to deliver the intervention to the group $(n=248$, mean age $=65$ years $)$ during five 2-hour sessions. The intervention also included a weekly 1 hour fitness session over 2 years led by a PT. The results of this trial showed no between group differences at 6 and 12 months in health related QoL, functional capacity, symptom control (e.g., diary of breathlessness), or COPD self-efficacy.

An RCT based in the UK examined an intervention that used a video to deliver the benefits of an exercise program (aerobic and strengthening) to patients with COPD ( $n=27$, mean age $=70$ years). Both the intervention and control group received 
an educational booklet about disease specific issues, medication, symptoms management, relaxation, risk modification and physical activity. All participants had an individual session with a PT where they discussed anxiety and benefits of exercise. The intervention group was then encouraged to perform the $30 \mathrm{~min}-$ ute videotaped home program $4 \mathrm{x}$ weekly for 6 weeks, which incorporated coaching, education and self-regulation strategies. The results showed an improvement in walking capacity (Incremental Shuttle Walk Test) [77], dyspnea associated with daily function (dyspnea, fatigue and emotions) and disease-specific quality of life. There was no significant between group differences in anxiety or depression [78]. Two of the three studies reviewed used a measure of mobility to assess the effect of the intervention [76, 78], and both of these studies used selfregulation strategies to deliver the intervention.

\section{Heart Disease}

A Canadian study examined the effects of using a structured multidisciplinary clinical pathway for older women with chronic heart failure (CHF) $(n=91$, mean age $=75$ years). The intervention included disease-specific education, physical activity which included both group and home exercise, nutrition, stress management and information about accessing resources; it was compared to usual care. A theoretical framework was not provided for the intervention. Education, coaching and selfregulation strategies were used to deliver the intervention $2 \mathrm{x}$ weekly for 6 weeks. Assessments at 6 weeks and 6 months showed there was no difference between the groups on the Heart Failure Questionnaire, Physical Functioning Scale, SF-36, MMSE or health service utilization. There was no measurement of physical performance or mobility [79].

\section{Generic Chronic Disease Programs}

A multi-component intervention (individualized PT and OT, risk assessment, chronic disease management and web-based education) was delivered to persons with chronic disease including back pain, diabetes, multiple sclerosis, stroke, Parkinson's Disease, cardiovascular disease, COPD, asthma, fibromyalgia, cancer, arthritis and obesity $(n=303)$ versus a control group who received usual care in a primary care setting. The CDSMP was a derivative of the Stanford program and included information linking rehabilitation principles such as FITT (frequency, intensity, time and type) principles for exercise and assistive devices to $\mathrm{CDM}$ and was delivered by the PT and OT $1 \mathrm{x}$ weekly for 6 weeks in a group format. An individual approach to SM was integrated into the PT/OT treatment intervention for persons who were unable to participate in the group sessions. The Social Cognitive Theory [67] and the Nagi framework [49, 80, 81] were both used in the development of the intervention.
There were significant positive effects for the intervention group for a health utilization measure (planned hospital days) and patient satisfaction but no between group differences on the SF-36, the Late-Life Function and Disability Instrument (LLFDI) or the performance measures (2MWT, the lower extremity performance test or grip strength). Self-management and self-efficacy measures also showed no difference although improved communication with physician approached significance. It is difficult to distinguish the contribution of the SM within this complex intervention, as the SM interventions themselves were not targeted sufficiently towards functional health and physiotherapeutic principles could have been more fully incorporated.

\section{Theoretical Components of SM Interventions}

Service delivery framework

Six studies $[62,66,75,79,82,83]$ included a service delivery outcome, although did not cite these in the context of the CCM; they all measured the same concept of health care utilization. Interestingly, a study that used a patient-practitioner collaboration model did not identify a service delivery component as a target within the SM intervention.

\section{Functioning Framework}

International classification of functioning Eleven studies included outcomes for the "body functions and structure", "activities" and "participation" concepts of the ICF (See Table 1). Only one study did not incorporate a measure of the "body functions and structure" concept of the ICF [79] and three studies omitted measures of "participation" [72, 74, 78].

Glass' model of functioning Five studies [59••, 63, 64, 74, 82] focused on measuring function at the hypothetical and experimental tenses. Three studies $[65,66,76]$ only measured function at the hypothetical tense. Four studies $[62,72,75$, 78 ] only measured function at the experimental tense. None of the studies included an outcome measurement of the enacted function.

Reserve capacity One study targeted increasing "functional reserve" indirectly by focusing only on cognitive-behavioral interventions to increase the amount of participants' physical activity $[57 \cdot \bullet$. The remaining interventions targeted increasing functional reserve directly by providing structured exercise programs to the participants. Six studies $[63,65,66,73$, $76,82]$ aimed to increase functional reserve by individually tailoring the exercise program using baseline assessments and progression of either frequency or intensity. Six studies [62, $64,74,75,78,79,83]$ prescribed a standardized exercise 
Table 2 SM interventions utilizing theoretical frameworks

\begin{tabular}{|c|c|c|c|c|}
\hline Study & $\begin{array}{l}\text { Theoretical } \\
\text { framework }\end{array}$ & $\begin{array}{l}\text { Evidence of theory } \\
\text { in the design of the } \\
\text { intervention }\end{array}$ & $\begin{array}{l}\text { Evidence of theory } \\
\text { in the delivery of the } \\
\text { intervention }\end{array}$ & $\begin{array}{l}\text { Evidence of theory } \\
\text { in outcomes } \\
\text { measured }\end{array}$ \\
\hline $\begin{array}{l}\text { Coleman }[57 \bullet \bullet] \\
\quad(2012)\end{array}$ & $\begin{array}{l}\text { Social Cognitive } \\
\text { Theory }\end{array}$ & $\begin{array}{l}\text { The intervention } \\
\text { included the } \\
\text { promotion of goal } \\
\text { setting, problem } \\
\text { solving, modeling, } \\
\text { positive thinking and } \\
\text { improving } \\
\text { self-efficacy. }\end{array}$ & $\begin{array}{l}\text { Intervention delivered } \\
\text { by health professionals. } \\
\text { The authors maintain } \\
\text { that the knowledge and } \\
\text { skill of a health professional } \\
\text { is essential to promote self- } \\
\text { efficacy and change } \\
\text { behavior. }\end{array}$ & $\begin{array}{l}\text { Measured self-reported } \\
\text { pain, stiffness, physical } \\
\text { function, } \\
\text { QoL. Objective measures } \\
\text { of } \\
\text { performance (mobility, } \\
\text { ROM, strength). } \\
\text { No measure of self- } \\
\text { efficacy used. }\end{array}$ \\
\hline $\begin{array}{c}\text { Hopman-Rock } \\
\text { [62] (2000) }\end{array}$ & $\begin{array}{l}\text { Self-management } \\
\text { principles (Lorig) }\end{array}$ & $\begin{array}{l}\text { The group education } \\
\text { (peer-led) sessions } \\
\text { included goal } \\
\text { planning and peer } \\
\text { support. The exercise } \\
\text { program (PT-led) } \\
\text { contained no evidence } \\
\text { of SM principles. }\end{array}$ & Not described & $\begin{array}{l}\text { Used multiple outcomes, } \\
\text { not all validated. } \\
\text { Measured } \\
\text { self-reported pain, QoL, p } \\
\text { hysical function health } \\
\text { care utilization. Objective } \\
\text { measures of ROM, } \\
\text { strength, } \\
\text { mobility. Self-efficacy } \\
\text { was } \\
\text { a secondary outcome } \\
\text { (Arthritis Self-Efficacy } \\
\text { Scale, controlling } \\
\text { symptoms } \\
\text { subscale) }\end{array}$ \\
\hline $\begin{array}{l}\text { Hughes [73] } \\
\text { (2006) }\end{array}$ & $\begin{array}{l}\text { Social Cognitive } \\
\text { Theory, Process } \\
\text { Model } \\
\text { for Patient- } \\
\text { Practitioner } \\
\text { Collaboration and } \\
\text { Negotiated } \\
\text { Adherence Model } \\
\text { (Jensen and } \\
\text { Lorish) }\end{array}$ & $\begin{array}{l}\text { Intervention included } \\
\text { a group discussion- } \\
\text { educational component } \\
\text { to enhance self-efficacy } \\
\text { for exercise (adapted } \\
\text { from Kovar 1992). } \\
\text { Participants identified } \\
\text { outcomes they hoped to } \\
\text { achieve through exercise; } \\
\text { they were provided with } \\
\text { feedback on progress } \\
\text { made toward achieving } \\
\text { these goals. Post- } \\
\text { intervention exercise plans } \\
\text { were developed following } \\
\text { the negotiated adherence } \\
\text { model. This involved } \\
\text { signing an exercise } \\
\text { contract and keeping } \\
\text { an exercise log. }\end{array}$ & $\begin{array}{l}\text { Trainers followed } \\
\text { the process model } \\
\text { for patient-practitioner } \\
\text { collaboration to enhance } \\
\text { self-efficacy for } \\
\text { adherence to exercise. } \\
\text { Involved goal setting, } \\
\text { barrier identification, } \\
\text { problem solving. }\end{array}$ & $\begin{array}{l}\text { Self-efficacy was the } \\
\text { primary } \\
\text { outcome (Efficacy for } \\
\text { Arthritis Self- } \\
\text { Management, } \\
\text { exercise, pain and other s } \\
\text { ymptoms subscale and the } \\
\text { Adherence Self-Efficacy } \\
\text { scales). } \\
\text { Also measured self- } \\
\text { reported } \\
\text { pain, stiffness } \\
\text { physical function and } \\
\text { objective measures of } \\
\text { strength and exercise } \\
\text { capacity. }\end{array}$ \\
\hline $\begin{array}{l}\text { Richardson [82] } \\
\text { (2010) }\end{array}$ & $\begin{array}{l}\text { Social Cognitive } \\
\text { Theory, chronic } \\
\text { disease } \\
\text { self-management } \\
\text { principles } \\
\text { (Stanford Model) }\end{array}$ & $\begin{array}{l}\text { Intervention included collaborative } \\
\text { goal setting } \\
\text { for rehabilitation needs } \\
\text { and participation in a } \\
\text { Rehabilitation Self-Management } \\
\text { Program (based on the Stanford } \\
\text { CDSMP) with a focus on } \\
\text { self-management of } \\
\text { physical function. }\end{array}$ & & $\begin{array}{l}\text { Measured self-reported } \\
\text { QoL, } \\
\text { function, satisfaction and } \\
\text { health } \\
\text { care utilization. Objective } \\
\text { measures of } \\
\text { exercise capacity, lower } \\
\text { extremity } \\
\text { performance } \\
\text { and strength. Self-efficacy } \\
\text { and SM behaviours were } \\
\text { secondary } \\
\text { outcomes. }\end{array}$ \\
\hline
\end{tabular}

$[63-66,74-76,78,79,83]$ did not describe a theoretical framework in the development or delivery of their SM intervention 
program to all participants, which did not include individualization (tailoring) or progression.

\section{Behavioral Framework}

Only two studies [59••, 64] did not include an outcome related to individual behavior. The remaining studies included outcome measurements of self- efficacy, and some also included measurements of treatment adherence [72], self-regulation [75], and self-control [76, 78]. Table 2 outlines how four of the studies reviewed used a theoretical framework (primarily SCT) to develop, deliver and evaluate their SM intervention. Three of these studies measured self-efficacy as an outcome, but also assessed a variety of other outcomes using self-report and performance measures. This is important, since selfefficacy is a mediator in behavior change; it is also essential to demonstrate that SM interventions modify other key health outcomes.

\section{Discussion}

Approaches to managing increasing patient complexity and chronicity will not be met with guidelines for single diseases. As function is likely to be a focus of care for both patient and practitioner, the focus of management for persons with chronic and complex conditions should be on understanding functional capacity and resolving issues with respect to functional status [84].

In this paper we reviewed studies in which PTs delivered SM interventions to older persons. Only nine of the 15 studies measured mobility and the assessments used included the 2MWT and the 6MWT, the TUG, the 8-foot walk test (as part of the lower extremity performance test) and the Incremental Shuttle Walk Test. Five out of the 15 studies reported positive findings in the functional outcomes reported [59••, 63, 65, 66, 78] . When mapped to the ICF classification of functioning, there were more positive findings at the level of body functions and structure in the arthritis studies compared to the COPD studies, where there were more positive findings at the level of participation The largest emphasis in assessment was in body functions and structure (the impairment level of functioning) and the fewest measures were at the level of participation. Self- management programs have traditionally targeted symptoms as a way of managing and stabilizing the disease process by lessening acute exacerbations. However, physical therapists can offer unique contributions to SM interventions by targeting activity and participation levels. This approach to optimizing functional health for persons with chronic disease should be through the promotion of regular physical activity as is evidenced in this current review. Eleven studies used a performance measure to assess functional activity [59••, 62, 63, 65, 66, 72, 75, 76, 78, 82, 85] and only two of these studies reported significant differences for the intervention group [59••, 78]. Future focus needs to be directed at maximizing mobility, specifically walking. Even for individuals with functional limitations, slower paced walking and adapted exercise can improve function. Most studies aimed to increase the functional reserve of participants directly, and half of these studies accomplished this by tailoring and progressing the exercise intervention. Based on the theoretical concept of "functional capacity" as the ability to adapt to physical demanding stimulus, it is important that the physical activity components of SM interventions include the concepts of tailoring and progression to achieve a training effect and achieve greater functional reserve.

A meta-analysis of SM programs for older adults with arthritis, hypertension, and diabetes examined 53 RCTs and found that there was evidence that SM interventions reduced haemoglobin $\mathrm{A}_{1 \mathrm{C}}$ and blood pressure in diabetes and hypertension groups but had little effect on pain and function for persons with arthritis [86]. It has been suggested in the literature that to make any meaningful conclusion about SM interventions, standardization of various components of the interventions and the outcomes measured needs to be undertaken $[86,87]$.

Jansma (2010) has made an important contribution to synchronizing and integrating the approaches between the delivery of SM and rehabilitation interventions. She describes that they both strive to optimize functioning to allow people to participate fully in life, they are both goal orientated (using self-selected goals), are patient-centred and take a problem solving approach to delivering care. This occurs in coordination with the rehabilitation team and with consideration of learning principles and teaching skills. However one of the fundamental differences is that the CDSMP is often delivered by a lay facilitator compared to the rehabilitation intervention which is delivered by professional [88]. The program by Coleman et al. (2008) is an example of how SM programs incorporating musculoskeletal principles and rehabilitation strategies should be structured and implemented. They argue for the role of PTs as well as other health professionals in the delivery of SM where the added benefit may be a result of modeling and more detailed knowledge about the condition and adapted functioning. They emphasize the importance of the skill and expertise offered by health professionals rather than the empathy and support offered by lay leaders. There were long term improvements for patients who undertook the OAK program which have not been demonstrated in other

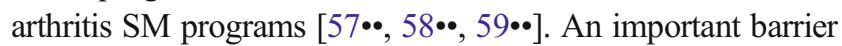
to participation of the PACE program was the lack of physical challenge provided by the program [63]. This is easily rectified in programs delivered by physical therapists who can use their expertise in musculoskeletal function to tailor interventions to the needs of participants. 
A classification system for mobility and function is needed to clarify communication about function and facilitate the targeting of physical therapy interventions. There is the opportunity for physical therapists to increase the link between primary care (with rehabilitation based self- management programs) and public health (with adaptive participation in community based programs) by integrating their clinical work into community based approaches to promote functional health at individual and population levels.

\section{Conclusions}

Future research and development needs to focus on the core professional principles, theoretical frameworks and the integration of rehabilitation derived SM into PT practice. SM programs led by PTs need to have a mobility measurement component with a performance measure in the outcomes. There is evidence PTs can provide expertise about conditions and adapted functioning which can help overcome some barriers to participation and result in positive health outcomes.

\section{Compliance with Ethics Guidelines}

Conflict of Interest Julie Richardson, Vanina Dal Bello-Haas, Adalberto Loyola-Sanchez, Joy MacDermid, and Susanne Sinclair declare that they have no conflict of interest.

Human and Animal Rights and Informed Consent This article does not contain any studies with human or animal subjects performed by any of the authors.

\section{References}

Papers of particular interest, published recently have been highlighted as:

- Of importance

•- Of major importance

1. The World Health Organization. World Report on Disability. Geneva: The World Health Organization; 2011.

2. The World Health Organization. The global burden of disease: 2004 update. Geneva: The World Health Organization; 2008.

3. - Lin J, Whitlock E, Eckstrom E, Fu Rongwei F, Perdue L, Beil T, et al. Challenges in synthesizing and interpreting the evidence from a systematic review of multifactorial interventions to prevent functional decline in older adults. J Am Geriatr Soc. 2012;60:2157-66. This paper is an excellent overview of the issues in researching functional decline associated with aging and with combining different studies.

4. Richardson J, Loyola-Sanchez A, Sinclair S, Harris J, Letts L, MacIntyre N, Wilkins S, Burgos-Martinez G, Wishart L, McBay C et al. Self-management interventions for chronic disease: A scoping review. Submitted to Clin Rehabil. 2013

5. Gruman J, Von Korff M. Indexed bibliography on self-management for people with chronic disease. Washington: Center for Advancement in Health; 1996.
6. Timmreck TC. Dictionary of health services management, 2nd ed: National Health Pub.; 1987.

7. Lorig K, Holman H. Self-management education: history, defintion, outcomes and mechanisms. Ann Behav Med. 2003;26:1-7.

8. - Dattalo M, Giovannetti E, Scharfstein D, Boult C, Wegener S, Wolff $\mathrm{J}$, et al. Who participates in chronic disease self-management (CDSM) programs? Differences between participants and nonparticipants in a population of multimorbid older adults. Med Care. 2012;50:1071-5. This paper identifies factors associated with persons who have chronic disease but may be more difficult to recruit to programs and so will identify for clinicians which groups may need different strategies.

9. Schuurmans H, Steverink N, Lindenberg S, Frieswijk N, Slaets JP. Old or frail: What tells us more? J Gerontol A-Biol. 2004;59A(9):962-5.

10. Steverink N, Slaets JPJ, Schuurmans H, Van Lis M. Measuring frailty: developing and testing the GFI (Gronigen Frailty Indicator). Gerontologist. 2001;41:236.

11. Wagner E, Grothaus L, Hecht JA, et al. Factors associated with participation in a senior health promotion program? Gerontologist. 1991;31:598-602.

12. Bode C, De Ridder D. Investing in the future- identifying participants in an educational program for middle-aged and older adults. Health Educ Res. 2007;22:473-82.

13. Bruce B, Lorig K, Laurent D. Participation in patient selfmanagement programs. Arthritis Rheum. 2007;57:851-4.

14. Munter P, Sudre P, Uldry C, et al. Predictors of participation and attendance in a new asthma patient self-management education program. Chest. 2001;120:778-84.

15. Blanch D, Rudd R, Wright E, et al. Predictors of refusal during a mutli-step recruitment process for randomised controlled trial arthritis education. Patient Educ Couns. 2008;73:280-5.

16. Watkins A, Kligman E. Attendance patterns of older adults in a health promotion program. Public Health Rep. 1993;108:86-90.

17. Saunders K, Von Korff M, Grothaus L. Predictors of participation in primary care group-format back pain self-care interventions. Clin J Pain. 2000;16:236-43.

18. Dodge J, Clark N, Janz N, et al. Non-participation of older adults in a heart-disease self-management project- factors influencing involvement. Res Aging. 1993;15:220-37.

19. Institute of Medicine. Crossing the Quality Chasm: A New Health System for the 21st Century. Washington, DC: National Academy Press, Institute of Medicine; 2001.

20. Bierman AS. Functional status - the sixth vital sign. J Gen Intern Med. 2001;16:785-6.

21. Richardson J, Letts L, Chan D, Officer A, Wojkowski S, Oliver D, et al. Monitoring physical functioning as the sixth vital sign: evaluating patient and practice engagement in chronic illness care in a primary care setting - A quasi-experimental design. BMC Fam Pract. 2012;13:1-13.

22. - Min L, Wanted SP. A FRAME for staging functional decline in older adults. J Am Geriatr Soc. 2012;60:2167-8. This paper discusses the issues around the lack of a framework to describe older adults who have different levels of functioning and could be seen as a challenge to physical therapists to develop this framework.

23. Patla A, Shumway CA. Dimensions of mobility: defining the complexity and difficulty associated with community mobility. J Aging Phys Activity. 1999;7:7-19.

24. Gill T, Williams CS, Richardson ED, Tinnetti ME. Impairments in physical performance and cognitive status as predisposing factors for functional dependence among nondisabled older persons. J Gerontol A-Biol. 1996;51:M283-8.

25. Cesari M, Kritchevsky SB, Penninx BW, Nicklas B, Simonsick EM, Newman A, et al. Prognostic value of usual gait speed in wellfunctioning older people- Results from the Health, Aging and Body Composition study. J Am Geriatr Soc. 2005;53:1675-80.

26. Gill TM GAH, Hardy SE, Guo Z. The dynamic nature of mobility disability in older persons. J Am Geriatr Soc. 2006;54:248-54. 
27. Manty M, Heinonen A, Leinonen R, Tormakangas T, Sakari-Rantala $\mathrm{R}$, Hirvensalo $\mathrm{M}$, et al. Construct and predictive validity of a selfreported measure of preclinical mobility limitation. Arch Phys Med Rehabil. 2007;88:1108-13.

28. Fried LP, Bandeen-Roche K, Chaves P, Johnson B. Preclinical disability predicts incident mobility disability in older women. J Gerontol A-Biol. 2000;55:889-901.

29. Fried LP, Young Y, Rubin G, Bandeen-Roche K. Self-reported preclinical disability identifies older women with early declines in performance and early disease. J Clin Epidemiol. 2001;54(9):889-901.

30. Shumway Cook A, Ciol MA, Yorkston KM, Hoffman JM, Chan L. Mobility limitations in the Medicare populations: prevalence and sociodemographic and clinical correlates. J Am Geriatr Soc. 2005;53:1217-21.

31. Khokhar SR, Stern Y, Bell K, Anderson K, Noe E, Mayeux R, et al. Persistent mobility deficit in the absence of deficits in actvities of daily living: A risk factor for mortality. J Am Geriatr Soc. 2001;49:1539-43.

32. Hasegawa R, Islam M, Lee S, Koizumi D, Rogers M, Takeshima N. Threshold of lower body muscular strength necessary to perform ADL independently in community-dwelling older adults. Clin Rehabil. 2008;22:902-10.

33. Fukagawa N, Brown M, Sinacore D, Host H. The relationship of strength to function in the older adult. J Gerontol A-Biol. 1995;50A:55-9.

34. Rantanen T, Avela J. Leg extension power and walking speed in very old people living independently. J Gerontol A-Biol. 1997;52:M225231.

35. Rantanen T, Guralnik JM, Ferrucci L, et al. Coimpairments as predictors of severe walking disability in older women. J Am Geriatr Soc. 2001;49:21-7.

36. Fiser WM, Hays NP, Rogers SC, et al. Energetics of walking in elderly people: factors related to gait speed. J Gerontol A-Biol. 2010;65:1332-7.

37. Hicks GE, Shardell M, Alley DE, et al. Absolute strength and loss of strength as predictors of mobility decline in older adults: the InCHIANTI study. J Gerontol A-Biol. 2011;67A:66-73.

38. - Bohannon R, Williams A. Normal walking speed: A descriptive metaanalysis. Physiotherapy. 2011;97:182-9. This article describes normal gait speed for healthy individuals using age and gender subgroups.

39. Fried LP, Ferrucci L, Darer J, Williamson JD, Anderson G. Untangling the concepts of disability, frailty, and comorbidity: implications for improved targeting and care. J Gerontol A-Biol. 2004;59:255-63.

40. Montero-Odasso M, Muir SW, Hall M, et al. Gait variability is associated with frailty in community-dwelling older adults. J Gerontol A-Biol. 2011;66:568-76.

41. Guralnik JM, Simonsick EM, Ferrucci L, Berkman LF, Blazer G, Wallace PA. A short physical performance battery assessing lower extremity function: association with self-reported disability and prediction of mortality and nursing home admission. J Gerontol. 1994;2:M85-94.

42. Guralnik J, Fried L, Pieper CF, Leveille SG, Markides KS, Ostir GV, et al. Lower extremity function and susequent disability: consistency across studies, predictive models, and value of gait speed alone compared with short physical performance battery. J Gerontol ABiol. 2000;55:M221-231.

43. Ogilvie D, Foster C, Rothnie H, Cavill N, Hamilton V, Fitzsimmons $\mathrm{C}$, et al. Interventions to promote walking: A systematic review. BMJ. 2007;334:1204.

44. - Barr V, Robinson S, Marin-Link B, Underhill L, Dotts A, Ravensdale D, et al. The expanded chronic care model: An integration of concepts and strategies from population health promotion and the chronic care model. Hospital Quarterly. 2003;7:73-82. This article expands on the CCM by Wagner and includes population health by linking the primary care portion to the community.
45. Wagner EH, Austin BT, Von Korff M. Organizing care for patients with chronic illness. Milbank Q. 1996;74:511-44.

46. Wagner EH. Chronic disease management: What will it take to improve care for chronic illness? Effective Clinical Practice. $1998 ; 1: 2-4$

47. Wagner EH, Austin BT, Davis C, Hindmarsh M, Schaefer J, Bonomi A. Improving chronic illness care: Translating evidence into action. Health Affairs. 2001;20:64-78.

48. Nagi S. An epidemiology of disability among adults in the United States. Milbank Q. 1976;54:439-68.

49. Verbrugge L, Jette A. The disablement process. Soc Sci Med. 1994;38:1-14.

50. Glass TA. Conjugating the tenses of function: Discordance among the hypothetical, experimental, and enacted function in older adults. Gerontologist. 1998;38:101-12.

51. Bonder BR, Wagner M, editors. Functional performance in older adults, 2nd edition. Philadelphia: F.A. Davies; 2001.

52. Maes S, Karoly P. Self-regulation assessment and intervention in physical illness. Appl Psychol. 2005;54:267-99.

53. Karoly P. Toward consensus in the psychology of self-regulation: how far have we come? how far do we have yet to travel? Appl Psychol-Int Rev. 2005;54:300-11.

54. Bandura A. The primacy of self-regulation in health promotion. Appl Psychol-Int Rev. 2005;54:245-54.

55. Bandura A, editor. Social foundations of thought and action. 1986.

56. Bandura A. Health promotion by social cognitive means. Health Educ and Behav. 2004;31:143-64.

57. •• Coleman S, Briiffa N, Conroy H, Prince R, Carroll G, McQuade J. Effects of self-management, education and specific exercises, delivered by health professionals, in patients with osteoarthritis of the knee. BMC Musculoskel Dis. 2008;9:133. This paper details the actual SM intervention used in the trial and was the most detailed description of a SM intervention and could be used as a prototype.

58. •• Coleman S, Briiffa N, Carroll G, Inderjeeth C, Cook N, McQuade J. Short and medium-term effects of an education self-management program for individuals with osteoarthritis of the knee, designed and delivered by health professsionals: a quality assurance study. BMC Musculoskel Dis. 2008;9:117. This paper details the actual SM intervention used in the trial and was the most detailed description of a SM intervention and could be used as a prototype.

59. • Coleman S, Briffa N, Carroll G, Inderjeeth C, Cook N, McQuade J. A randomised controlled trial of a self-management education program for osteoarthritis of the knee delivered by health care professionals. Arthritis Res and Ther. 2012;14:1-14. This paper describes the trial with the largest number of positive outcomes as a result of SM for older adults.It was also the intervention with the most detailed description (see above).

60. Podsiadlo D, Richardson S. The timed "up and go": a test of basic functional mobility for frail elderly persons. J Am Geriatr Soc. 1991;39:142-8.

61. Huiskes C, Kraaimaat F, Bijlsma J. Development of a self-report questionnaire to assess the impact of rheumatic disease on helath and lifestyle. J Rehabil Sci. 1990;3:71-4.

62. Hopman-Rock M, Westhoff MH. The effects of a health educational and exercise program for older adults with osteoarthritis of the hip or knee. J Rheumatol. 2000;27:1947-54

63. Callahan LF, Mielenz T, Freburger J, Shreffler J, Hootman J, Brady T, et al. A randomized controlled trial of the people with arthritis can exercise program: symptoms, function, physical activity, and psychosocial outcomes. Arthirtis Care Res. 2008;59:92-101.

64. Bennell KL, Hinman RS, Metcalf BR, Buchbinder R, McConnell J, $\mathrm{McColl} \mathrm{G}$, et al. Efficacy of physiotherapy management of knee joint osteoarthritis: a randomised, double blind, placebo controlled trial. Ann Rhem Dis. 2005;64:906-12.

65. Hurley MV, Walsh NE, Mitchell HL, Pimm TJ, Patel A, Williamson E, et al. Clinical effectiveness of a rehabilitation program integrating 
exercise, self-management, and active coping strategies for chronic knee pain: A cluster randomized trial. Arthritis Rheum. 2007;57:1211-9.

66. Jessep SA, Walsh NE, Ratcliffe J, Hurley MV. Long-term clinical benefits and costs of an integrated rehabilitation programme compared with outpatient physiotherapy for chronic knee pain. Physiotherapy. 2009;95:94-102.

67. Bandura A. Self-efficacy: Toward a unifying theory of behaviour change. Psychol Rev. 1977;84:191-215.

68. Kovar P, Allegrante J, Mackenzie C, Peterson M, Gutin B, Charlson M. Supervised fitness walking in aptients with osteoarthritisof the knee. Ann of Intern Med. 1992;116:529-34.

69. Jensen G, Lorish C. Promoting patient cooperation with exercise programs: Linking research, theory, and practice. Arthritis Care Res. 1994;7:181-9.

70. Guyatt G, Sullivan M, Thompson P, Fallen E, Pugsley S, Taylor DW, et al. The 6-minute walk: a new measure of exercise capacity in patients with chronic heart failure. Can Med Assoc J. 1985;132:919.

71. Guralnik JM, Pieper CF, Leveille S, Markides KS, Ostir GV. Lower extremity function and subsequent disability: Consistency across studies, predictive models, and value of gait speed alone compared with short physical performance battery. J Gerontol A-Biol. 2000;55:M221231.

72. Hughes SL, Seymour RB, Cambell RT, Huber G, Pollak N, Sharma L, et al. Long-term impact of Fit and Strong! on older adults with osteoarthritis. Gerontologist. 2006;46:801-14.

73. Hughes SL, Seymour R, Campbell R, Pollack N, Huber G, Sharma L. Impact of the Fit and Strong intervention on older adults with osteoarthritis. Gerontologist. 2004;44:217-28.

74. Devereux K, Robertson D, Briffa N. Effects of water-based program on women 65 years and over: A randomised controlled trial. Aust J Physiother. 2005;51:102-8.

75. Bourbeau J, Julien M, Maltais F, Rouleau M, Beaupre A, Begin R, et al. Reduction of hospital utilization in patients with chronic obstructive pulmonary disease - A disease-specific self-management intervention. Arch Intern Med. 2003;163:585-91.

76. Monninkhof E, Van der Valk J, van der Palen J, van Herwaarden C, Zielhuis G. Effects of a comprehensive self-management programme in patients with chronic obstructive pulmonary disease. Eur Respir. 2003;22:815-20.

77. Singh S, Morgan M, Walters D, Hardman A. Development of a shuttle walking test of disability in patients with chronic airways obstruction. Thorax. 1992;47:1019-24.

78. Moore J, Fiddler H, Seymour J, Grant A, Jolley C, Johnson L, et al. Effect of a home exercise video programme in patients with chronic obstructive pumlonary disease. J Rehabil Med. 2009;41:195-200.

79. Azad N, Molnar F, Byszewski A. Lessons learned from a multidisciplinary heart failure clinic for older women: a randomised controlled trial. Age Ageing. 2008;37:282-7.

80. Jette AM. Towards a common language of function, disability and health. Phys Ther. 2006;86:726-34.

81. Jette A. Physical disablement concepts for physical therapy research and practice. Phys Ther. 1994;74:380-6.

82. Richardson J, Letts L, Chan D, Stratford P, Hand C, Price D, et al. Rehabilitation in a primary care setting for persons with chronic illness - a randomized controlled trial. Primary Health Care Research \& Development. 2010;11:382-95.

83. Maltais F, Bourbeau J, Lacasse Y, Shapiro S, Perrault H, Penrod JR, et al. A Canadian, multicentre, randomized clinical trial of homebased pulmonary rehabilitattion in chronic obstructive pulmonary disease: Rationale and methods. Can Respir J. 2005;12:193-8.

84. Upshur E, Tracy S. Chronicity and complexity. CMAJ. 2008;54:1655-8.

85. Chodosh J, Morton S, Mojica W, Magloine M, Suttorp M, Hilton L, et al. Meta-analysis: Chronic disease self-management programs for older adults. Ann Intern Med. 2005;143:427-38.

86. Warsi A, Wang PS, LaValley MP, Avorn J, Solomon DH. Selfmanagement education programs in chronic disease: a systematic review and methodological critique of the literature. Arch Intern Med. 2004;164:1641-9.

87. Jansma FI, Twillert SV, Postema K, Sanderman R, Letttinga AT. Physical and rehabilitation medicine and self-management education: A comparative analysis of two approaches. J Rehabil Med. 2010;42:808-14.

88. Jansma FI, Lettinga AT. On making a difference: The case of selfmanagement education and physical and rehabilitation medicine. $\mathrm{J}$ Rehabil Med. 2011;43:465-6. 